\section{The Cochrane test}

(1) Consider anything that works

(2) Make effective treatments available to all

(3) Minimise ill timed interventions

(4) Treat patients in the most cost effective place

(5) Prevent only what is preventable

(6) Diagnose only if treatable

than no treatment or alternative treatments, and one should screen only for treatable or preventable problems. In 1972 Cochrane called cervical smears "the saddest sin of commission in the NHS." (The worst sins of omission were antismoking programmes and preventing unwanted pregnancies.) The incidence of cervical cancer was rare and it was still more rare to find at treatable stage, Cochrane argued, and its death rate fell at the same rate before mass screening began as after.

Cochrane would have shaken his head in disbelief at the way prevention protocols in the new general practitioner contract make the government pay for measures well beyond what the evidence shows to be reasonable. ${ }^{6}$

\section{(6) Diagnose only if treatable}

Cochrane understood 20 years ago that doctors like to make diagnoses. Accurate, even insightful, diagnosis has long earned the profession respect, even if nothing can be done. Soon, advances in microbiology and genetics will enable us to identify disorders and predict them before they happen, far beyond what we can treat. Outside research, Cochrane thought such diagnostics were a professional indulgence that signals to the patient that effective treatment will follow when it may not.

\section{How the NHS scores}

How does the NHS or any other system score on the Cochrane test?

The NHS would come out fairly well on items 2 (making treatments available) and 6 (diagnosing only treatable disorders), better than many other systems, but it would come out worse on 4 (treat in the most cost effective place) and 5 (prevent only preventable conditions) and poorly on items 1 (test effectiveness) and 3 (test effectiveness at different times). So would almost every other system. In short, virtually every health care system in the world has a long way to go in meeting these six criteria for cost effective care.

It makes little sense for a health care system to become preoccupied with managerial efficiency if it does not first determine which services are worth providing, and where and when, and which services should be dropped. Once a health care system scores well on the Cochrane test most of its inefficiencies will be eliminated. This is precisely what needs based budgeting and purchasing can accomplish. The Cochrane test provides guidelines for health authorities and directors of public health as they take up this rare opportunity to allocate funds wisely by measuring the levels of dysfunction and pain in the population and then purchasing the services that most effectively reduce them.

I thank A W Macara, consultant in public health medicine, University of Bristol, for his careful review and suggestions on an earlier draft. 1 Light DW. Learning from their mistakes? Health Service fournal 1990;5221:
1470-2.

2 Light DW. Bending the rules. Health Service fournal 1990;5222:1513-5.

3 Light DW. Embedded inefficiencies. Lancet (in press).

4 Cochrane A. Effectiveness and efficiency: random reflections on health services. London: Nuffield Provincial Hospitals Trust, 1972.

5 Gonnella JS, Louis DZ, Zeleznik C, Turner BJ. The problem of late hospitalization: a quality and cost issue. Academic Medicine 1990;65:314-9. 6 Audit Commission. A short cut to better services: day surgery in England and Wales. London: HMSO, 1990.

(Accepted 14 October 1991)

\title{
Health and the Environment
}

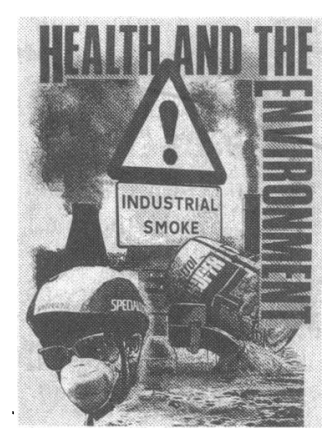

\section{Health implications of climatic change}

\author{
Fiona Godlee
}

Every age has its catastrophe theory. In the past decade alone scientists have threatened us with a new ice age and a nuclear winter. Now two new threats confront us, global warming and the destruction of the ozone layer, linked by their origin in man's pollution of the environment. Both have enormous implications for health. This article will examine the potential impacts of global warming on health. Next week's article will examine the dangers of ozone depletion.

\section{Global warming}

Without some form of insulating layer to trap heat from the sun the earth could not sustain life. Its surface temperature would be $40 \mathrm{~K}$ lower and the oceans would freeze.' Insulation, largely in the form of atmospheric carbon dioxide, allows the passage of visible and ultraviolet light from the sun while preventing too much of the solar heat that radiates from the earth's surface from escaping. But the amount of carbon dioxide and other insulating, or greenhouse, gases in the atmosphere is now rising fast, with potentially damaging effects on the earth's climate and on human health.

Carbon dioxide is produced by animals and plants and the burning of fossil fuels. Because trees fix carbon from the air, levels of carbon dioxide are also increased by deforestation. Each year 17 million hectares of tropical forest are being destroyed - an area the size of Austria. ${ }^{2}$ In the past hundred years, since the beginning of the industrial revolution, the concentration of carbon dioxide in the atmosphere has increased by a quarter and is currently increasing at a rate of about $0.5 \%$ a year. ${ }^{3}$ Concentrations are now higher than at any time in the past 16000 years. ${ }^{4}$ In 1988 the world produced five billion tonnes of carbon dioxide, and the atmospheric concentration was estimated at 352 parts per million. ${ }^{\prime}$ If in the next 100 years consumption of fossil fuels doubles - a conservative estimate-the concentration may rise to 600 parts per million: twice the level in $1850 .^{5}$

In terms of sheer bulk atmospheric carbon dioxide is the main contributor to the greenhouse effect. But other gases present in the atmosphere-methane, 


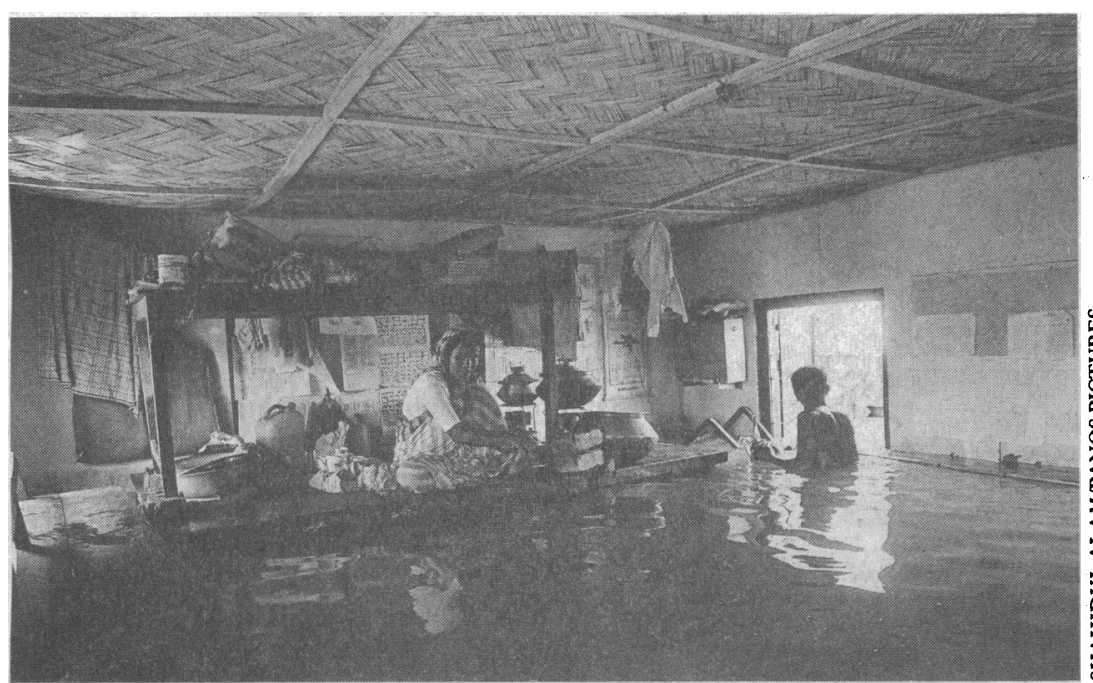

A quarter of Bangladesh could disappear underwater

nitrous oxide, and chlorofluorocarbons-are all more effective insulators, and their combined impact almost equals that of carbon dioxide (table) ${ }^{6}$ Ozone, released at ground level as a result of the action of sunlight on urban air pollutants, also contributes to the greenhouse effect, as does water vapour.

The type and magnitude of changes that may result from the greenhouse effect are the subject of much controversy. In the past 100 years the earth's surface temperature has risen by an average of $0 \cdot 6^{\circ} \mathrm{C}$ (figure). This could be a blip, but, according to proponents of the greenhouse theory, it is a sign that global warming is already occurring. Further increases of $2-5^{\circ} \mathrm{C}$ over the next 50 to 100 years have been predicted. This change is equivalent to the difference in temperature between the last ice age and now.

Global warming could affect health both directly, by changing current patterns of disease, and indirectly, through its impact on sea level and on the availability of agricultural land and water for irrigation. ${ }^{8}$

\section{Direct effects of global warming on health}

People, especially those who are elderly, very young, or sick, are not good at dealing with extremes of temperature. In temperate climates the main concern is usually the effects of excessively cold weather

Concentrations, growth rates, atmospheric lifetimes and contributions to global warming of main greenhouse gases $^{x}$

\begin{tabular}{|c|c|c|c|c|c|}
\hline & \multicolumn{2}{|c|}{ Atmospheric concentration } & \multirow{2}{*}{$\begin{array}{c}\text { Current } \\
\text { rate of } \\
\text { change/year }\end{array}$} & \multirow{2}{*}{$\begin{array}{l}\text { Atmospheric } \\
\text { lifetime } \\
\text { (years) }\end{array}$} & \multirow{2}{*}{$\begin{array}{c}\text { Contribution } \\
\text { to global } \\
\text { warming } \\
\text { during 1980s } \\
(\%)\end{array}$} \\
\hline & $\begin{array}{c}\text { Preindustrial } \\
(1750-1800)\end{array}$ & 1990 & & & \\
\hline Carbon dioxide (parts per million) & 280 & 353 & $1.8(0.5 \%)$ & $50-200^{\star}$ & 55 \\
\hline Methane (parts per million) & $0 \cdot 8$ & 1.72 & $0.015(0.9 \%)$ & 10 & 15 \\
\hline Chlorofluorocarbon-11 (parts per million) & & 280 & $9 \cdot 5(4 \%)$ & 65 & \\
\hline Chlorofluorocarbon- 12 (parts per million) & & 484 & $17(4 \%)$ & 130 & 17 \\
\hline Nitrous oxide (parts per 1000 million) & 288 & 310 & $0.8(0 \cdot 25 \%)$ & 150 & 5 \\
\hline
\end{tabular}

* The way in which carbon dioxide is absorbed by the oceans and biosphere is complex and a single value cannot be given.

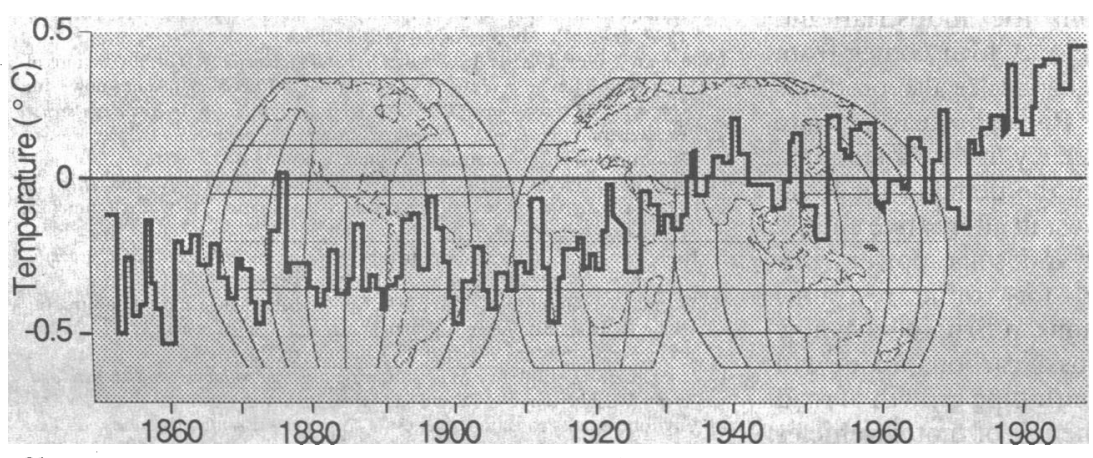

Changes in world temperatures in the past 140 years $(0=1950-80$ average $)$. Adapted from $F$ Pearce ${ }^{6}$ causing hypothermia and exacerbations of chronic lung disease. But hot weather also holds its dangers. During heat waves in Los Angeles the mortality is two to four times higher than normal, and up to eight times normal in those aged over $85 .^{9}$ Mortality from coronary heart disease and stroke increases when the average temperature exceeds $25^{\circ} \mathrm{C},{ }^{10}$ and predictive models suggest that above $33^{\circ} \mathrm{C}$ mortality from all causes increases, mainly owing to deaths from cardiovascular and respiratory disease. With a doubling of carbon dioxide concentrations, the number of summer deaths in the United States could increase sevenfold. Even taking into account acclimatisation and the likely reduction in winter deaths, models still predict an overall increase in mortality (L S Kalkstein et al, international conference on ozone modification and climate change, Washington, DC, June 1986).

Changes in temperature and humidity could also mean the appearance in temperate, industrialised countries of a number of diseases that are currently limited to the tropics. The United States, for example, could acquire mosquito borne diseases such as malaria, dengue fever, arbovirus encephalitides, yellow fever, and Rift Valley fever."

Debate continues about whether the greenhouse effect will cause meteorological upset, leading to more storms and natural disasters. ${ }^{12}$ If it does the world will have to contend not only with the immediate effects of death and disability but with the longer term sequelae of post-traumatic reactions, disabling psychiatric symptoms, and problems with psychological development in children. ${ }^{8}$

\section{Indirect effects of global warming}

The most easily comprehensible of the many potential consequences of global warming is the rise in sea level caused by the melting of glaciers and the polar ice caps. The size of this effect is controversial, and successive estimates have been increasingly conservative. In 1988, the talk was of a $6 \mathrm{~m}$ rise if the west Antarctic ice sheet were to melt. ${ }^{13}$ In 1989 the United States Environmental Protection Agency predicted a rise of $0.5-2 \mathrm{~m}$ by $2100 .{ }^{14}$ And in 1990 the International Panel on Climate Change estimated that during the next century the rise would not exceed $1 \mathrm{~m} .{ }^{15}$ This year the American National Academy of Sciences took an even more conservative line, estimating that an increase in temperature of $5^{\circ} \mathrm{C}$ would cause a maximum rise in sea level of $0.6 \mathrm{~m} .{ }^{3}$ This would be due mainly to thermal expansion because of increasing temperature and salinity. The academy concluded that substantial melting of the ice caps was unlikely but warned that unpredictable factors, such as the release of large amounts of methane from melting tundra, could have dramatic effects.

A rise in sea level of $1 \mathrm{~m}$ would mean the loss of large areas of inhabitable and agricultural land. One estimate puts the amount of land at risk from such a rise at 5 million $\mathrm{km}^{2}$-an area comprising only about $3 \%$ of the earth's total land area but encompassing one third of the world's crop growing land and the homes of one billion people. ${ }^{7}$ A $1 \mathrm{~m}$ rise in sea level would create 50 million environmental refugees-more than three times the number of all refugees today. ${ }^{4}$ Low lying, densely populated areas would be most vulnerable. About a quarter of Bangladesh could disappear under water, displacing up to a third of the population, and the habitats of 46 million people living along the Nile and the Ganges are potentially threatened. America could lose more than $19000 \mathrm{~km}$ of coast line around Florida and Miami, and areas of the Netherlands and the east coast of England could become submerged.

Water supplies from rivers and aquifers would become increasingly saline, and during the summer the 


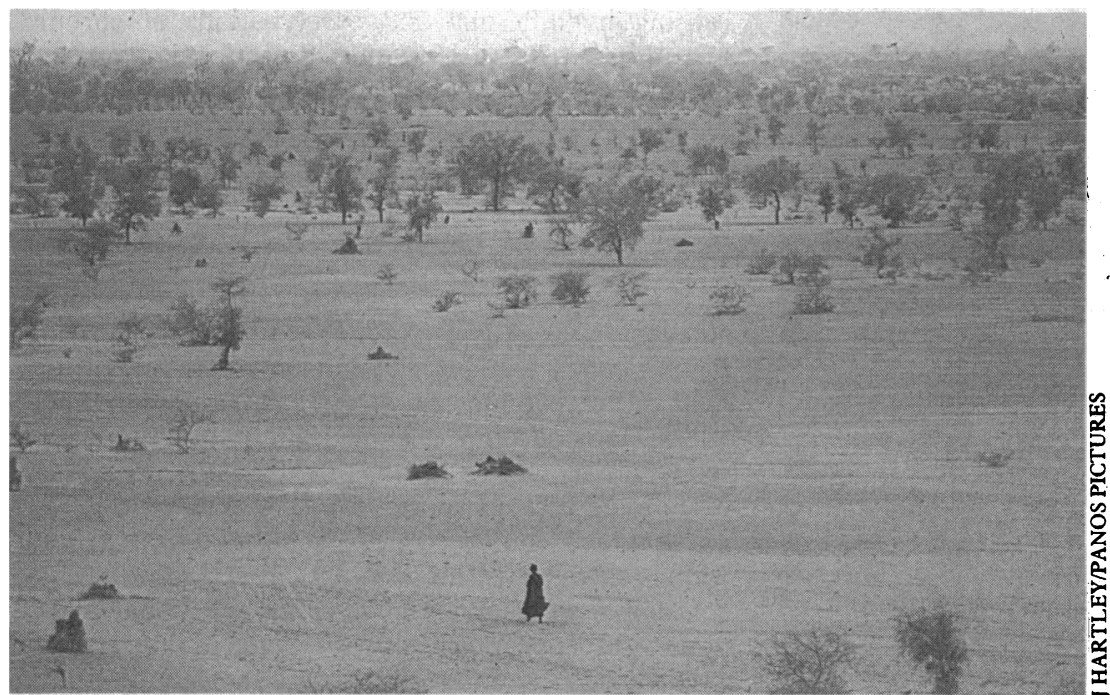

Changing rainfall patterns will transform fertile land into desert

amount and quality of available fresh water would fall. Changes in the patterns of rainfall could cause drought and desertification in currently fertile areas.

The predicted $20 \%$ increase in rain in winter and $5-10 \%$ reduction in summer would transform the grain belt in America's midwest - which provides $90 \%$ of the world's grain surplus -into desert. ${ }^{12} \mathrm{~A} 2^{\circ} \mathrm{C}$ rise in temperature could mean a decline in the wheat yields of Europe and North America of between $3 \%$ and $17 \%{ }^{16}$ Already in the past few years yields have fallen because of drought. In 1989 the world produced 18 million tons less grain than it consumed. An annual surplus of 28 million tons is needed to keep pace with population growth. ${ }^{2}$ Overall temperature conditions necessary for productive agriculture would shift northwards, away from the middle of the United States and Europe into Canada and Siberia. But these areas may not have adequate rainfall or sufficiently fertile soil to allow equivalent productivity.

Crops are also damaged by excessive exposure to ultraviolet light and so the destruction of the ozone layer will reduce yields. Meanwhile, a high level of ozone at ground level, produced by the effects of sunlight on urban air pollutants, is also damaging. It is estimated to have caused the loss of up to $10 \%$ of crops in the United States during the 1980s. ${ }^{17}$ the direct effects of drought and flood and the knock on effect of agricultural and economic decline in the West. The already present problems of feeding the world's growing population would be compounded by the increasing numbers of displaced people unable to grow their own food.

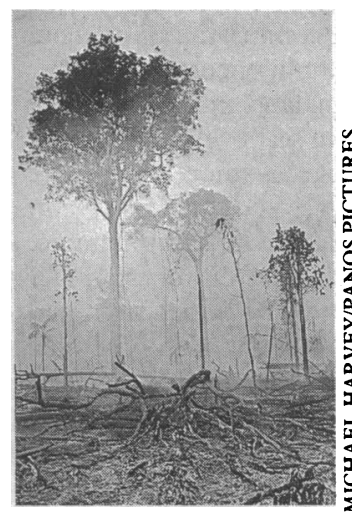

Each year $17 m$ hectares of tropical forest are destroyed

\section{What should be done}

The accumulation of greenhouse gases is largely the result of our dependence on fossil fuels for energy production. Nearly three quarters of Britain's carbon dioxide emissions result from the industrial and road traffic. Nitrous oxide and ozone are also products of fossil fuel consumption. Radical measures are needed to increase energy efficiency in power stations, industry, and homes to reduce the demand for fossil fuels. Governments should invest in alternative energy sources such as wind, wave, and solar power. But above all there is the need for traffic restraint. Industrial and domestic emissions in Britain have now stabilised, but by 2020 emissions of carbon dioxide will nearly double because of the continuing growth of road traffic. Policies for reducing the use of motor vehicles will be discussed in a later article.
Countries in the developing world would suffer both

Efforts to stall and reverse deforestation are also important. Sustainable forestry policies should be adopted and the demand for timber reduced by changing building practices and reducing waste and inefficiency.

Carbon dioxide has a long half life: half of the carbon dioxide produced since the start of the industrial revolution remains in the atmosphere today. ${ }^{5}$ Stabilising emissions is not the same as stabilising concentrations of gases in the atmosphere. The United States Environmental Protection Agency has estimated that to stabilise atmospheric concentrations of carbon dioxide, emissions will have to be cut by $50 \%$ to $80 \%{ }^{18}$ Individual countries have responded to this with varying amounts of enthusiasm. The Netherlands is committed to a $20 \%$ reduction in emissions by 2000 and Germany to a $25 \%$ reduction by 2005 . This may be increased to $30 \%$ as a result of policy changes since reunification. Britain has agreed only to stabilise emissions by 2005, and the United States and the Soviet Union have so far refused to agree to any limits at all.

\section{Conclusion}

Based, as all these predictions are, on scientific theories and modelling, they remain controversial. But while the debate continues so does the potentially disastrous accumulation of greenhouse gases. As with acute medical emergencies there is no time to wait for the return of the investigations which would confirm the diagnosis. It is necessary to act on the balance of probabilities rather than waiting, like criminal lawyers, for all reasonable doubt to be removed. Global warming may prove to be this decade's scare story, though the weight of scientific evidence makes that unlikely, but the risks of drastic climatic change are too great to ignore.

I am grateful to Professor Andrew Haines for help in preparing this article.

1 McElroy MB. The challenge of global change. Bulletin of the American Academy of Arts and Science 1989;42:25-38.

2 Brown LR, ed. State of the world 1991: a Worldwatch Institute report on progress toward a sustainable sociery. London: Earthscans Publications, 1991.

3 National Academy of Sciences. Policy implications of greenhouse warming. Washington DC, National Academy Press 1991.

4 Brown LR, ed. State of the world, 1989: a Worldwatch Institute report on progress Brown LR, ed. State of the world, 1989: a Worldwatch Institute
toward a sustainable society. New York: W W Norton, 1989.

Leaf A. Potential health effects of global climatic and environmental changes. N Engl f Med 1989;321:1577-83.

6 World Resources Institute. World resources 1990-91. New York: Basic Books, 1990:14.

6a Pearce F. Warmer winters fit greenhouse model. New Scientist 199 Jan 19:20.

7 Brown LR, ed. State of the world 1990: a Worldwatch Institute report on progress toward a sustainable society. New York: W W Norton, 1990.

8 Haines A, Fuchs C. Potential impacts on health of atmospheric change. f Public Health Med 1991;13:69-80.

9 Oeschli FW, Buckley RW. Excess mortality associated with three Los Angeles September hot spells. Environ Res 1970;3:277-84.

10 Rogot E, Padgett SJ. Associations of coronary and stroke mortality with temperature and snowfall in selected areas of the United States, 1952-1966. Am f Epidemiol 1976;103:565-75. domestic burning of fossil fuels. A fifth comes from 